\title{
Pulmonary function of patients with chronic rhinosinusitis and the impact of endoscopic sinus surgery Ahmed M. Youssef ${ }^{a}$, Osama G. Abdel-Naby Awad ${ }^{a}$, Mohamed Tahab
}

aHead and Neck Department, ${ }^{b}$ Chest Department, Minia University, Minia, Egypt

Correspondence to Osama G. Abdel-Naby Awad, MD, Head and Neck Department, Minia University, 122 Kornish El-Neel Street, Minia City, Minia - 61111, Egypt; Tel: 086-2373707; fax: +20 2086232505 ; e-mail: omarsmsm2014@yahoo.com

Received 14 December 2016 Accepted 13 January 2017

The Egyptian Journal of Otolaryngology 2018, 34:167-172

\begin{abstract}
Background
There is growing evidence that chronic rhinosinusitis (CRS) may be associated with lower airway manifestations. The difference in pulmonary function between normal individuals and patients with CRS and whether endoscopic sinus surgery (ESS) has a positive effect on the lower airway still remains controversial.

The aim of this study was to compare pulmonary function tests (PFTs) in normal individuals and CRS patients and to investigate the outcomes of ESS on PFTs in patients with CRS.
\end{abstract}

\section{Patients and methods}

A prospective study was carried out on 25 normal adults (group I) and 25 adult CRS patients (group II). PFTs were used to compare the lower airway condition between the two groups. Another comparison in PFTs was made in patients with CRS to evaluate the effectiveness of ESS at 1 week preoperatively and 1 month, postoperatively.

\section{Results}

In group I, all participants had forced expiratory volume in 1s (FEV1)/forced vital capacity (FVC) of at least $80 \%$, with a mean of $0.84 \pm 0.07$, compared with the preoperative FEV1/FVC values of group II, which ranged from 61 to $70 \%$ in five (20\%) patients, from 71 to $79 \%$ in $10(40 \%)$ patients, and were equal to or higher than $80 \%$ in $10(20 \%)$ patients. FEV1/FVC was significantly lower in group II patients than in group I participants $(P=0.04)$. At 1 month postoperatively, the FEV1/FVC values of group II ranged from 61 to $70 \%$ in two ( $8 \%$ ) patients, from 71 to $79 \%$ in $13(52 \%)$ patients, and were equal to or higher than $80 \%$ in $12(48 \%)$ patients; the mean FEV1/FVC was $0.9 \pm 0.50$. These values were significantly higher $(P=0.02)$ compared with the preoperative values.

\section{Conclusion}

This study provides corroborative objective evidence that patients with CRS may have nonmanifest lower airway infection compared with normal individuals and ESS is efficacious in the improvement of such infection.

\section{Keywords:}

chronic rhinosinusitis, endoscopic sinus surgery, pulmonary function test

Egypt J Otolaryngol 34:167-172

(C) 2018 The Egyptian Journal of Otolaryngology

$1012-5574$

\section{Introduction}

Chronic rhinosinusitis (CRS) is an inflammatory disease of the mucosa of the nasal cavity and paranasal sinuses with symptoms lasting longer than 12 weeks. It is a common disease and represents a public health problem, resulting in a socioeconomic burden throughout the world [1,2]. The pathogenesis of CRS is poorly understood; however, genetic susceptibility, infection, anatomic abnormalities, and local immunologic imbalance have been postulated to play roles in its pathogenesis [3-5]. Treatment options for CRS include medical therapy, surgical intervention, or a combination of both. According to current guidelines, the surgical approach is reserved for patients who fail to respond adequately to medical therapy. The most frequently used surgical technique is endoscopic sinus surgery (ESS) [6].
A close association has been suggested between sinusitis and lower respiratory disorders such as bronchial asthma. It is well known that chronic sinusitis coexists in as many as $40-75 \%$ of patients with asthma [7]. Clarifying and understanding the relationship between diseases of the upper and lower respiratory tract is important because of the prevalence of rhinosinusitis and asthma and the resulting burden on patients and the health care system [8].

Although clinical evidence is accumulating that CRS exacerbates lower airway disease, more direct and

\footnotetext{
This is an open access journal, and articles are distributed under the terms of the Creative Commons Attribution-NonCommercial-ShareAlike 4.0 License, which allows others to remix, tweak, and build upon the work non-commercially, as long as appropriate credit is given and the new creations are licensed under the identical terms.
} 
objective studies are needed to elucidate the important role that CRS may play in lower airway disease [9]. Direct evidence of an association could be obtained by examining the effect of treatment of CRS on pulmonary symptoms and functions. Appropriate medical treatment for CRS has been reported to have a beneficial effect on asthma symptoms $[10,11]$. The present study focuses on the difference in lung functions in patients with resistant CRS compared with normal individuals and also focuses on the benefits of ESS on lung functions in these patients.

\section{Patients and methods}

This prospective study was carried out in the Department of Otolaryngology, Head and Neck Surgery, Minia University Hospital, Minia, between January 2014 and January 2015. The study was approved by the Institutional Review Board at Minia University. Fifty adults were enrolled in the study and were divided into two groups: group I included 25 control normal participants and group II included 25 patients with CRS.

\section{Inclusion criteria}

We included in the study 25 adult normal participants and 25 adult patients with medically resistant CRS diagnosed according to the definition of the consensus report of the Rhinosinusitis Task Force [12] as the presence of symptoms and classic physical examination findings of CRS confirmed by soft tissue involvement of the paranasal sinuses on a computed tomography (CT) scan lasting for at least 3 months after maximal medical therapy.

\section{Exclusion criteria}

Patients with any of the following conditions were excluded: nasal polyps, nasal allergy, bronchial asthma, allergic fungal sinusitis, chronic obstructive pulmonary disease, cystic fibrosis, primary ciliary dyskinesia, immunodeficiency, pregnant women, co-existent systemic diseases such as diabetes, hypertension, neoplasia, patients with previous paranasal sinus surgery, and/or patients who did not attend their follow-up visits.

\section{Chronic rhinosinusitis assessment}

A subjective CRS assessment was performed on all patients reporting the following symptoms: nasal congestion, facial pain or pressure, headache, nasal discharge, olfactory disturbance, and overall discomfort.

\section{Computed tomography assessment}

The Lund-McKay CT scoring system [13] was used to separately assess the extent of the opacification of the individual sinuses and osteomatal complex and a score of 2,1 , or 0 was, respectively, assigned if there was complete, partial, or no opacification.

\section{Allergy assessment}

Allergy assessment was performed on the basis of the presence of at least one positive skin test on a panel of regionally relevant aeroallergens.

\section{Lower airway assessment \\ Clinical assessment}

Symptoms of the lower airway including cough, sputum, dyspnea, chest pain, wheezes, and hemoptysis were reported. We excluded patients with the diagnosis of asthma according to National Institute of Health guidelines for the diagnosis and management of asthma [14]. Chest radiographs (posterior-anterior and lateral views) were obtained for each patient to identify any concomitant disease in the lungs.

\section{Pulmonary function tests}

Pulmonary function tests (PFTs) were performed according to the standardization of lung function tests of the European Respiratory Society [15] using a spirometer (Lab Digital Spirometer 762600; Sensormedics, Homestead, Florida, USA).

In a normal case, forced vital capacity (FVC) and forced expiratory volume in one second (FEV1) should be greater than or equal to $80 \%$ of the predicted value for a patient's age, height, and weight. An obstructive ventilatory defect was defined as a decrease in FEV1 out of proportion to any decrease in $\mathrm{FVC}$, that is a decrease in the FEV1/FVC ratio. The severity of lower airway obstruction was assessed according to the following: an FEV1/FVC ratio ranging from 71 to $79 \%$ was considered mild obstruction, an FEV1/FVC ratio from 61 to $70 \%$ was considered moderate obstruction, and an FEV1/FVC ratio of $60 \%$ or less was considered severe obstruction [16].

PFTs were performed for group II patients at 1 week before and 1 month after ESS.

\section{Surgical steps}

A written and informed consent was obtained from the patients with CRS before ESS and patients were provided with all information including the details of their disease, the procedure, the risks of the procedure, and possible outcomes. ESS was performed under general anesthesia using the Messerklinger technique [6]. Patients with marked septal deviation obstructing one nasal cavity underwent septoplasty. An infundibulectomy was performed by incising the anterior attachment of the uncinate process. Then, the ethmoidal bulla was opened and removed piecemeal. The decision to open 
the maxillary antrum, explore the frontal recess, the posterior ethmoids, and the sphenoid depended on the extent of the disease as evidenced by the $\mathrm{CT}$ scan and operative findings. Merocel packs were left in the nasal cavities and the patient was kept in the hospital overnight and discharged in the morning.

\section{Follow-up}

Packs were removed after the $48 \mathrm{~h}$ and patients were prescribed antibiotics for $7-10$ days with alkaline nasal douching and an intranasal corticosteroid spray for 1 month postoperatively.

\section{Statistical analysis}

Statistical analysis was carried out using SPSS software (version 12.0; SPSS Inc., Chicago, Illinois, USA). Results are expressed as the mean and SD for continuous variables and as percentages for categorical variables. Data were compared using the $t$-test or a Mann-Whitney and a $\chi^{2}$-test as appropriate. $P$ of less than or equal to 0.05 was considered statistically significant.

\section{Results}

This study included two groups: group I included 25 normal control participants and group II included 25 patients with CRS and had undergone ESS. PFTs were measured in both groups. A comparison was made between the PFTs values of group I and preoperative PFTs of group II, and another comparison was made between the preoperative and postoperative PFTs values of patients of group II.

\section{Participants' characteristics \\ Age distribution}

The age of all the participants involved in the study ranged from 18 to 50 years, with a mean age of 27.1 \pm 6.86 years. Table 1 presents the age distribution in both groups, with no statistically significant difference between the two groups.

\section{Sex distribution}

There were $15(60 \%)$ men and $10(40 \%)$ women in group I and $12(48 \%)$ men and 13 (52\%) women in group II, with no significant difference between the two groups in terms of the sex distribution (Table 1).

\section{Demographic profile}

The weight of the participants in group I ranged from 55 to $78 \mathrm{~kg}$, with a mean of $67.45 \pm 6.3 \mathrm{~kg} / \mathrm{m}^{2}$ (Table 1 ). The weight of the patients in group II ranged from 60 to $88 \mathrm{~kg}$, with a mean of $69.7 \pm 9.72 \mathrm{~kg} / \mathrm{m}^{2}$. The height of the participants in group I ranged from 160 to $190 \mathrm{~cm}$, with a mean of $170.35 \pm 3.3 \mathrm{~cm}$. The height of the patients in group II ranged from 165 to $189 \mathrm{~cm}$, with a mean of
$172.56 \pm 4.5 \mathrm{~cm}$. There was no statistically significant difference between both groups in the demographic data and BMI.

\section{Smoking}

Five male participants in group I were smokers versus six male patients in group II, with no statistically significant difference in the smoking index between the two groups.

\section{Chronic rhinosinusitis symptoms}

Table 2 presents the different symptoms of CRS patients, with facial pain and headache being the most frequent symptoms.

\section{Computed tomography lund and mackey sinus score}

Table 2 presents the involvement of different sinus groups on CT scan for the patients of group II. The majority of patients had a score of 14 (nine cases). The most affected group of sinuses was the maxillary sinuses and the least affected group of sinuses was the sphenoid. Osteomatal complex was affected in $80 \%$ of patients.

\section{Lower airway assessment}

Lower airway symptoms

Table 3presents the distribution of chest symptoms, with chronic cough being the most frequent symptom.

\begin{tabular}{lccc}
\multicolumn{4}{c}{ Table 1 Population characteristics in group I versus group II } \\
\hline Demographic data & Group I $(n=25)$ & Group II $(n=25)$ & $P$ value \\
\hline Age (years) & & & 0.494 \\
$\quad$ Range & $18-49$ & $18-39$ & \\
$\quad$ Mean \pm SD & $28.95 \pm 9.83$ & $27.1 \pm 6.86$ & \\
Sex $[n(\%)]$ & & & 0.525 \\
$\quad$ Male & $15(60)$ & $12(48)$ & \\
Female & $10(40)$ & $13(52)$ & \\
Weight (kg) & & & 0.391 \\
$\quad$ Range & $55-78$ & $60-88$ & \\
$\quad$ Mean \pm SD & $67.45 \pm 6.3$ & $69.7 \pm 9.72$ & \\
Height (cm) & & & 0.449 \\
$\quad$ Range & $147-180$ & $158-170$ & \\
Mean \pm SD & $166.2 \pm 8.55$ & $164 \pm 3.68$ & \\
\hline
\end{tabular}

Group I $(N=25)$, normal participants; group II $(N=25)$, chronic rhinosinusitis patents. "Fisher exact test: $P \leq 0.05$ is significant.

Table 2 Computed tomography sinus score in the patients in group II

\begin{tabular}{lccccccc}
\hline & \multicolumn{3}{c}{ Right side (\%) } & & \multicolumn{3}{c}{ Left side (\%) } \\
\cline { 2 - 4 } \cline { 7 - 8 } & 0 & 1 & 2 & & 0 & 1 & 2 \\
\hline Frontal & 80 & 15 & 5 & & 90 & 5 & 5 \\
Maxillary & 5 & 80 & 15 & & 10 & 80 & 10 \\
Anterior ethmoidal & 15 & 70 & 15 & & 15 & 70 & $15 \%$ \\
Posterior ethmoidal & 25 & 65 & 10 & & 20 & 70 & 10 \\
Sphenoid & 80 & 10 & $10 \%$ & & 80 & 10 & 10 \\
OMC & 20 & - & 80 & & 20 & - & 80 \\
\hline
\end{tabular}

OMC, osteomatal complex. 
Table 3 Pulmonary function tests values: preoperative pulmonary function test values of group I versus group II

\begin{tabular}{lccc}
\hline & Group I $(n=25)$ & $\begin{array}{c}\text { Group II }(n=25) \\
\text { (preoperative values) }\end{array}$ & $P$ value $^{*}$ \\
\hline FVC (mean) & & & $0.02^{*}$ \\
Range & $2.5-5.17$ & $2.39-5.04$ & \\
Mean \pm SD & $3.94 \pm 0.88$ & $3.45 \pm 0.78$ & $<0.001^{*}$ \\
FVC (\%) & & & \\
Range & $87-113$ & $60-99$ & $0.05^{*}$ \\
Mean \pm SD & $99.95 \pm 9.27$ & $84.8 \pm 11.51$ & \\
FEV1 (mean) & & & \\
Range & $1.91-4.24$ & $2.17-4.05$ & \\
Mean \pm SD & $3.35 \pm 0.87$ & $3 \pm 0.54$ & \\
FEV1 $(\%)$ & & & \\
Range & $90-116$ & $74-109$ & \\
Mean $\pm S D$ & $103.15 \pm 9.84$ & $89.9 \pm 9.91$ & \\
FEV1/FVC & & & \\
Range & $0.76-0.95$ & $0.78-1$ & \\
Mean $\pm S D$ & $0.84 \pm 0.07$ & $0.88 \pm 0.7$ & \\
\hline
\end{tabular}

Group I $(N=25)$, normal participants; group II $(N=25)$, chronic rhinosinusitis patents. "Fisher exact test: $P \leq 0.05$ is significant.

Group I pulmonary function tests values versus group II preoperative pulmonary function tests values

In group I, FEV1 values ranged from 2.17 (90\% predicted) to 4.24 (116\% predicted), with a mean of $3.35 \pm 0.87$. FVC values ranged from 2.5 (87\% predicted) to 5.17 (113\% predicted) (Table 3). In all participants, FEV1/FVC was $\geq 80 \%$. The mean FEV1/FVC was $0.84 \pm 0.07$.

In group II, the preoperative FEV1 values ranged from 1.91 (74\% predicted) to 4.05 (109\% predicted), with a mean of $3 \pm 0.54$. FVC values ranged from 2.29 (60\% predicted) to 5.04 (99\% predicted). FEV1/FVC ranged from 61 to $70 \%$ in five (20\%) patients, from 71 to $79 \%$ in 10 (40\%) patients, and was equal to or higher than $80 \%$ in 10 (20\%) patients. The mean FEV1/FVC was 0.88 \pm 0.7 .

There was a statistically significant difference in FEV1 mean and FEV1\% between the two groups ( $P=0.05$ and $P<0.001$, respectively), with better values in group I. Also, there was a statistically significant difference in FVC mean and $\mathrm{FVC} \%$ between the two groups $(P=0.02$ and $P<0.001$, respectively), with better values in group $\mathrm{I}$.

FEV1/FVC was significantly lower in the patients in group II than the participants in group $I(P=0.04)$.

\section{Change in pulmonary function tests in group II (preoperative and postoperative values)}

Postoperative values: FEV1 values ranged from 2.36 (83\% of predicted) to 4.86 (125\% of predicted), with a mean of $3.9 \pm 0.53$. FVC values ranged from
Table 4 Pulmonary function tests values: group II (preoperative vs. postoperative) values

\begin{tabular}{cccc}
\hline & \multicolumn{2}{c}{ Group II $(n=25)$} & $\begin{array}{c}P \\
\text { value }\end{array}$ \\
\cline { 2 - 3 } & $\begin{array}{c}\text { Preoperative } \\
\text { PFTs }\end{array}$ & $\begin{array}{c}\text { Postoperative } \\
\text { PFTs }\end{array}$ \\
\hline FVC (mean) & & & $0.033^{*}$ \\
$\quad$ Range & $2.39-5.04$ & $2.62-5.02)$ & \\
Mean \pm SD & $3.45 \pm 0.78$ & $3.57 \pm 0.81$ & \\
FVC (\%) & & & $<0.001^{*}$ \\
Range & $60-99$ & $72-109$ & \\
Mean \pm SD & $84.8 \pm 11.51$ & $91.4 \pm 11.09$ & \multirow{2}{*}{$0.033^{*}$} \\
FEV1 & & & \\
(mean) & & & \\
Range & $2.17-4.05$ & $2.36-3.86$ & \\
Mean \pm SD & $3 \pm 0.54$ & $3.09 \pm 0.53$ & \\
FEV1 $(\%)$ & & & \\
Range & $74-109$ & $83-125$ & \\
Mean $\pm S D$ & $89.9 \pm 9.91$ & $99.1 \pm 13.17$ & \\
FEV1/FVC & & & $0.02^{*}$ \\
Range & $0.78-1$ & $0.77-0.95$ & \\
Mean \pm SD & $0.88 \pm 0.7$ & $0.88 \pm 0.6$ & \\
\hline
\end{tabular}

Group II $(N=25)$, chronic rhinosinusitis patents. "Fisher exact test: $P \leq 0.05$ is significant.

2.62 (72\% of predicted) to 5.8 (109\% of predicted) (Table 4). FEV1/FVC ranged from 61 to $70 \%$ in two (8\%) patients, from 71 to $79 \%$ in $13(52 \%)$ patients, and was equal to or higher than $80 \%$ in 12 (48\%) patients. The mean FEV1/FVC was 0.9 0.5 .

There was a statistically significant difference in FEV1 mean and $\mathrm{FEV} 1 \%(P=0.03$ and 0.001 , respectively), with better postoperative values. Also, there was a statistically significant difference in FVC mean and FVC\% ( $P=0.02$ and 0.001 , respectively), with better postoperative values.

FEV1/FVC was significantly higher in postoperative values $(P=0.02)$ compared with preoperative values.

\section{Discussion}

Rhinosinusitis significantly impacts quality-of-life measures, with decrements in general health perception, vitality, and social functioning comparable with those observed in patients who have angina or chronic obstructive pulmonary disease [17]. This disease is also one of the main reasons why antibiotics are prescribed and for lost productivity in the work force [18]. Scientists have long recognized that diseases coexist in the upper and lower airways. The concept of 'united airways' implies that there is a link between upper and lower airway inflammation. In the second century, Galen noted the association between nasal symptoms and asthma, and advocated purging the nostrils of secretions to relieve the lower airways [19]. 
This prospective study was carried out in a tertiary referral institution to compare the PFTs of normal individuals and PFTs of patients with medically resistant CRS and to assess the impact of ESS on PFTs of these patients by comparing the preoperative and postoperative values. The study included patients of varied age groups, of varied socioeconomic status, and of both sexes. The results were compared with the available literature.

In this study, 11 (45\%) patients had a CT score in the range of $10-14$. In a study carried out by Wang et al. [20], 51.3\% of their patients had a CT score in the range of 2-4. These findings suggest that the majority of CRS patients have presented to our hospital at a relatively late stage of the disease. The most common group of sinuses involved in patients was the maxillary sinus, which was involved in all patients; this finding is in agreement with most of the published data [21].

Several studies have addressed the coexistent sinusitis and asthma, and reported that a proper treatment of diseased paranasal sinuses can significantly improve asthma symptoms [22-24]. However, there is a paucity of published literature on the nature of lower airway involvement in nonasthmatic patients with CRS. Ragab et al. [25], in their study, found different kinds of lower airway involvement in 60\% of adult CRS patients who failed medical treatment; some are manifest such as asthma and others are nonmanifest such as bronchial hyperreactivity. They also showed that the presence of nasal polyps was a risk factor for the involvement of the lower airways. Kariya et al. [26] also reported that pulmonary functions were affected in patients with CRS irrespective of their sensitization status. In the present study, we excluded patients with nasal polyps and nasal allergy and it was clearly evident that lung functions were better in normal individuals compared with medically resistant CRS patients.

This nonsymptomatic lower airway involvement in patients with CRS can be explained by the small lower airway dysfunction, which involves the terminal and respiratory bronchioles under $2-3 \mathrm{~mm}$ in diameter [27]; when the disease mainly involves the conducting airways, it is called small airway disease. Another entity of lower airway functional involvement is the inflammation of the lower airways resulting in bronchial hyper-reactivity [28]. The findings of this study also draw attention to the role of nasal obstruction in the development of lower airway disease, in which the nasal function is bypassed with loss of its function of cleaning, warming, and humidifying the inhaled air and loss of its protective mechanisms [29]. Nasal obstruction can induce a blockage of the sinus ostia with a reduction in the availability of nitric oxide in the upper and lower airways, which was reported in patients with chronic sinus disease [30]. Shturman examined the effect of nasal breathing versus mouth breathing in patients with asthma during exercise or hyperventilation, resulting in worsened pulmonary function with mouth breathing versus nasal breathing [31].

There are only a few reports using lung functions to evaluate the impact of sinus surgery in CRS patients. Karuthedath et al. [32] evaluated the impact of ESS on the PFTs of patients with CRS; on the whole, patients benefited from ESS with better PFTs. However, their study did not have a control group of normal participants. Other studies have shown that patients with CRS and asthma may benefit from ESS. In a previous study, we reported a significant effect of ESS on the PFTs and asthma outcome parameters in patients with bronchial asthma and nasal polyps [33]. The exact mechanism of the improvement of PFTs that occurred in patients with CRS after ESS is unclear. It is likely that part of the improvement after ESS occurs because of removal of trigger areas in the nose and sinuses that can induce the release of leukotrienes, prostaglandins, and other inflammatory mediators that may affect the lower airways [34]. Importantly, there was also a significant improvement in the FEV1/FVC value at 1 month postoperatively in our patients; these results reflect the effect of ESS on relieving the nonsymptomatic lower airway obstruction. These results may also be attributed to the postoperative usage of intranasal corticosteroid sprays that may lead to significant reductions in both upper and lower airway responses to intense triggers [35].

Although this study is limited by a relatively small number of studied patients, this prospective study, with its well-defined outcome measures and criteria included for patient selection, would help to clarify the actual value of ESS for these difficult-to-treat patients and to emphasize that the underuse of objective testing such as spirometry in patients with CRS may lead to underdiagnosed lower airway problems. Early diagnosis and good CRS control are important to reduce morbidity and healthcare costs as well as to minimize the development of chronic illnesses. 


\section{Conclusion}

This study provides corroborative objective evidence that patients with CRS may have nonmanifest lower airway infection compared with normal individuals and ESS is efficacious in the improvement of such infection.

\section{Financial support and sponsorship \\ Nil.}

\section{Conflicts of interest}

There are no conflicts of interest.

\section{References}

1 Plis JR, Ward BW, Lucas JW. Summary health statistics for US adults. National health interview survey 2009. Vital Health Stat 2010; 294: 1-207.

2 [No authors listed]. Infectious rhinosinusitis in adults: classification, etiology and management. International Rhinosinusitis Advisory Board. Ear Nose Throat J 1997; 76:1-22.

3 Chan Y, Kuhn FA. An update on the classifications, diagnosis, and treatment of rhinosinusitis. Curr Opin Otolaryngol Head Neck Surg 2009; 17:204-208.

4 Dass K, Peters AT. Diagnosis and management of rhinosinusitis: highlights from the 2015 practice parameter. Curr Allergy Asthma Rep 2016; 16:29-30.

5 Tint D, Kubala S, Toskala E. Risk factors and comorbidities in chronic rhinosinusitis. Curr Allergy Asthma Rep 2016; 16:16-17.

6 Stammberger H, Posawetz W. Functional endoscopic sinus surgery. Concept, indications and results of the Messerklinger technique. Eur Arch Otorhinolaryngol 1990; 247:63-76.

7 Dinis P, Gomes A. Sinusitis and asthma: how do they interrelate in sinus surgery? Am J Rhinol 1997; 11:421-428.

8 Eli O, Javier S, Michael W. Allergic rhinitis, asthma, and rhinosinusitis: diseases of the integrated airway. J Manag Care Pharm 2004; 10: 310-317.

9 Jang AS. The role of rhinosinusitis in severe asthma. Korean J Intern Med 2013; 28:646-651.

10 Levy JM, Rudmik L, Peters AT, Wise SK, Rotenberg BW, Smith TL. Contemporary management of chronic rhinosinusitis with nasal polyposis in aspirin-exacerbated respiratory disease: an evidence-based review with recommendations. Int Forum Allergy Rhinol 2016; 6: 1273-1283.

11 Dessouky O, Hopkins C. Surgical versus medical interventions in CRS and nasal polyps: comparative evidence between medical and surgical efficacy. Curr Allergy Asthma Rep 2015; 15:66.

12 Lanza DC, Kennedy DW. Adult rhinosinusitis defined. Otolaryngol Head Neck Surg 1997; 117:1-7.

13 Lund VJ, Mackay IS. Staging in rhinosinusitis. Rhinology 1993; 31:183-184.

14 Sheffer AL. The National Asthma Education Program attacks asthma. J Allergy Clin Immunol 1991; 87:468-469.

15 Pellegrino R, Viegi G, Brusasco V, Crapo RO, Burgos F, Casaburi R, et al. Interpretative strategies for lung function tests. Eur Respir J 2005; 26 : 948-968.
16 Damm M, Quante G, Jungehuelsing M, Stennert E. Impact of functional endoscopic sinus surgery on symptoms and quality of life in chronic rhinosinusitis. Laryngoscope 2002; 112:310-315.

17 Batra PS, Kern RC, Tripathi A, Conley DB, Ditto AM, Haines GK 3rd, et al. Outcome analysis of endoscopic sinus surgery in patients with nasal polyps and asthma. Laryngoscope 2003; 13:1703-1706.

18 Benninger MS, Ferguson BJ, Hadley JA, Hamilos DL, Jacobs M, Kennedy DW, et al. Adult chronic rhinosinusitis: definitions, diagnosis, epidemiology, and pathophysiology. Otolaryngol Head Neck Surg 2003; 129:S1-32.

19 Nair S, Bhadauria RS, Sharma S. Effect of endoscopic sinus surgery on asthmatic patients with chronic rhinosinusitis. Otolaryngol Head Neck Surg 2010; 62:285-288.

20 Wang PC, Chu CC, Liang SC, Tai CJ. Outcome predictors for endoscopic sinus surgery. Otolaryngol Head Neck Surg 2002; 126 : 154-159.

21 Ogunleye AO, Fasunla AJ. Radiological changes and complications associated with nasal polyposis. West Afr J Med 2004; 23:111-113.

22 Ikeda K, Tanno N, Tamura G. Endoscopic sinus surgery improves pulmonary function in patients with asthma associated with chronic sinusitis. Ann Otol Rhinol Laryngol 1999; 108:355-359.

23 Nakamura $\mathrm{H}$, Kawasaki M, Higuchi $\mathrm{Y}$, Takahashi S. Effects of sinus surgery on asthma in aspirin triad patients. Acta Otolaryngol 1999; 119:592-598.

24 Amar YG, Frenkiel S, Sobol SE. Outcome analysis of endoscopic sinus surgery for chronic sinusitis in patients having Samter's triad. J Otolaryngol 2000; 29:7-12.

25 Ragab A, Clement P, Vincken W. Objective assessment of lower airway involvement in chronic rhinosinusitis. Am J Rhinol 2014; 18:16-21.

26 Kariya S, Okano M, Higaki T, Noyama $\mathrm{Y}$, Haruna $\mathrm{T}$, Ishihara $\mathrm{H}$, et al. Chronic rhinosinusitis patients have decreased lung function. Int Forum Allergy Rhinol 2014; 44:828-833.

27 Takahashi M, Murata K, Takazakura R, Nakahara T, Shimizu K, Minese M, Itoh $\mathrm{H}$. Bronchiolar disease: spectrum and radiological findings. Eur $\mathrm{J}$ Radiol 2000; 35:15-29.

28 Sterk PJ, Fabbri LM, Quanjer PH, Cockcroft DW, O'Byrne PM, Anderson SD, et al. Airway responsiveness. Standardized challenge testing with pharmacological, physical, and sensitizing stimuli in adults. Report Working Party Standardization of Lung Function Tests, European Community for Steel and Coal. Official Statement of the European respiratory Society. Eur Respir J Suppl 1993; 16:53-83.

29 Togias A. Mechanisms of nose-lung interaction. Allergy 1999; 57: 94-105.

30 Maniscalco M, Sofia M, Pelaia G. Nitric oxide in upper airways inflammatory diseases. Inflamm Res 2007; 56:58-69.

31 Shturman-Ellstein R, Zeballos RJ, Buckley JM, Souhrada JF. The beneficial effect of nasal breathing on exercise induced bronchoconstriction. Am Rev Respir Dis 1978; 118:65-73.

32 Karuthedath S, Singh I, Chadha S. Impact of functional endoscopic sinus surgery on the pulmonary function of patients with chronic rhinosinusitis: a prospective study. Indian J Otolaryngol Head Neck Surg 2014; 66: 441-448.

33 Awad OG, Fasano MB, Lee JH, Graham SM. Asthma outcomes after endoscopic sinus surgery in aspirin-tolerant versus aspirin-induced asthmatics. Am J Rhinol 2008; 22:197-203.

34 Jung TT, Juhn SK, Hwang D, Stewart R. Prostaglandins, leukotrienes, and other arachidonic acid metabolites in nasal polyps and nasal mucosa. Laryngoscope 1987; 97:184-189.

35 Wood RA, Eggleston PA. The effect of intranasal steroids on nasal and pulmonary responses to cat exposure. Am J Respir Crit Care Med 1995; 151:315-320. 